Revue de l'Institut des langues et cultures

d'Europe, Amérique, Afrique, Asie et Australie

$46 \mid 2022$

Refuges identitaires numériques

\title{
Los contramarcos en las redes sociales: feminismos de lo subalterno
}

Les contre-cadres dans les réseaux sociaux: les féminismes subalternes

Counter-frames in Social Network: Subaltern Feminism

\section{Cristina García Martínez}

\section{(2) OpenEdition}

\section{Journals}

Edición electrónica

URL: https://journals.openedition.org/ilcea/13980

DOI: 10.4000/ilcea.13980

ISSN: 2101-0609

\section{Editor}

UGA Éditions/Université Grenoble Alpes

\section{Edición impresa}

ISBN: 978-2-37747-331-1

ISSN: $1639-6073$

\section{Referencia electrónica}

Cristina García Martínez, "Los contramarcos en las redes sociales: feminismos de lo subalterno», ILCEA [En línea], 46 | 2022, Publicado el 02 marzo 2022, consultado el 04 marzo 2022. URL: http:// journals.openedition.org/ilcea/13980 ; DOI: https://doi.org/10.4000/ilcea.13980

Este documento fue generado automáticamente el 4 marzo 2022.

(C) ILCEA 


\title{
Los contramarcos en las redes sociales: feminismos de lo subalterno
}

\author{
Les contre-cadres dans les réseaux sociaux : les féminismes subalternes \\ Counter-frames in Social Network: Subaltern Feminism
}

\section{Cristina García Martínez}

\section{Introducción}

[N]uevas formas de subactivismo evolucionan en torno a Internet con capacidad añadida para atravesar eficazmente el continuo privado-público y hacer que el compromiso cívico esté profundamente embebido en la vida cotidiana. (Bakardjieva, 2009: 102)

1 El advenimiento de Internet, y particularmente el de las redes sociales, sentó un antes y un después en la era contemporánea. La propagación de plataformas como Facebook, Twitter, Instagram o YouTube alentó la creación de espacios de lucha para diferentes movimientos sociales y políticos como la Primavera Árabe (Masip, Ruiz-Caballero \& Suau, 2019) o más recientemente la lucha del movimiento estadounidense Black Lives Matter (Olson, 2021). Siguiendo la estela de estos activismos, emergen en diferentes redes sociales grupos de feminismos de los márgenes (Ballestrin, 2017) ${ }^{1}$ creando espacios de diálogo, de apertura, de lucha y de reivindicación donde su praxis es su sello de identidad. Para ilustrar las construcciones de los contramarcos de estos feminismos, se ha seleccionado la mayor red social del mundo: Facebook. «Desde su aparición en 2004, su popularidad ha ido incrementándose, llegando en marzo de 2015 a 936 millones de usuarios diarios.» (Batorski \& Grzywińska, 2017: 361)

2 Pero ¿cómo funcionan los contramarcos en la red social más conocida? Las redes sociales imitan lo que Habermas, citado por Brenne (2016: 271) denomina «[...] la esfera pública, en el sentido de que proporcionan una plataforma para comunicar ideas relacionadas con el bien público». Este es el caso de la cuenta activista seleccionada, 
que a través del empleo de una iconografía como es la imagen, desde los márgenes y lo no académico, crea un contramarco como respuesta a los marcos establecidos (Feagin, 2000). No obstante, dicha iconografía no es arbitraria, sino que corresponde de manera específica a una voluntad de auto presentación de una narrativa determinada en función de la comunidad. Así, las imágenes expuestas en sus redes, a través de la asociación de ideas mentales sistemáticas, permitirán a las usuarias y a los usuarios identificar una lógica determinada atribuyéndole una serie de cualidades socioculturales (Joly, 2018). De esta forma, las redes sociales revelan una doble función: la de producción de imagen y reproducción de un imaginario, teniendo lugar esta última gracias al compartir de las usuarias y de los usuarios.

3 En este artículo se analiza la praxis y representación que la cuenta de activismo feminista subalterno «Paz y Género» hace en la red social Facebook. Enmarcada en los feminismos no hegemónicos, tanto por procedencia geográfica (Espinosa, 2017) como por temática abordada, emplea la imagen en su definición más extensa, como medio para denunciar y reclamar derechos, pero también compartir dinámicas propias a su grupo. Para la descripción y análisis de estas imágenes, retomaremos el concepto de contramarco y su funcionamiento abordados por Feagin (2020). El objetivo principal de este estudio es entender cómo se generan estos contramarcos, en signo de respuesta a los marcos sociales mainstream que imperan en el mundo online.

4 La selección de la red social Facebook se ha escogido en base a criterios formales. El primero de ellos radica en su antigüedad, siendo la primera red social de todas, y el segundo en su indiscutible popularidad (Batorski \& Grzywińska, 2017). Por otra parte, la selección de la cuenta «Paz y Género» se ha llevado a cabo por el interés social (Tortajada, Caballero-Gálvez \& Willem, 2019) que suscita el desarrollo de este grupo activista sustentado en la organización civil con el fin de contribuir a la construcción y visibilización de los contramarcos. Asimismo, se destaca un interés académico en cuanto al modelo que encarnan como espacios públicos de lucha y cambio.

Para la realización del análisis de las imágenes, se aplicará la metodología expresada por Tortajada, Caballero-Galvéz y William (2019). Es necesario recordar que «[b]uena parte de la teoría feminista procede de mujeres privilegiadas que viven en el centro, cuyas perspectivas pocas veces incluyen el conocimiento de las mujeres que viven en los márgenes» (hooks, 2015: 24). De este modo, en un primer momento y atendiendo a los marcos imperantes, se abordará el análisis de dos imágenes publicadas por los medios de comunicación nobles (prensa). A modo de contraste y como objetivo principal de este trabajo, se atenderá a los contramarcos de los feminismos de los márgenes o feminismos subalternos, que cuestionan el feminismo hegemónico en virtud de un feminismo más representativo. Estudiar la cuenta de «Paz y Género» implica retomar una visibilidad a menudo opacada por los medios mainstream. Con el objetivo de analizar cómo se construyen estos activismos, se ha revisado toda la producción de imágenes de dicha cuenta. Seguidamente, se ha realizado una selección de cuatro imágenes - de etapas diferentes- que por temática resultan las más representativas de sus narrativas. A lo largo del análisis fotográfico, se atenderá a una metodología esencialmente aperturista basada en aspectos cualitativos (Denzin, 2012) donde los marcos y contramarcos emergen a partir del análisis de los aspectos formales (número de «me gusta» obtenidos, número de usuarias y usuarios que comparten y número de comentarios) y de los aspectos analíticos basados en el enfoque 
constructivista del sociólogo Hall (1973-1977-2010) con el objetivo de cuestionar las representaciones de las imágenes.

\section{Los marcos y contramarcos: conceptos de un cambio}

6 El sociólogo estadounidense Feagin (2020: 195) define los contramarcos como «[...] marcos que proporcionan perspectivas alternativas o contrarias a la estructura blanca dominante». Desde la etapa colonial, las sociedades occidentales han creado un imaginario específico para definir al otro. A través de su obra, Feagin (2020: 4) acuña el «[...] marco racial blanco a la realidad opresiva del racismo sistémico tal y como opera en la actualidad» es decir «[...]un marco racial dominante que durante mucho tiempo ha legitimado, racionalizado, motivado y dado forma a la opresión y la desigualdad racial».

7 En este sentido, y retomando nuestro objeto de estudio, el feminismo de los márgenes podría definirse por inferencia como un contramarco del feminismo hegemónico blanco. El afrofeminismo, feminismo indígena, o ampliamente el feminismo subalterno, son activismos que nacen para cubrir el vacío presentado por los feminismos hegemónicos.

\subsection{Redes sociales como espacio seguro}

8 Las redes sociales pueden considerarse medios de comunicación alternativos, en oposición a los medios de comunicación convencionales, pues toda o todo cibernauta puede participar de manera autónoma en la construcción de las narrativas. De este modo, se afirma que «[l]as plataformas de la Web 2.0 permitieron la creación de contenidos de base, las interacciones dinámicas y la creación de comunidades» (Batorski \& Grzywińska, 2017: 357). Facebook, red social sobre la que se trabajará más tarde, permite la creación de un espacio abierto donde convergen usuarias y usuarios que comparten intereses comunes y que, de otra forma, probablemente no existirían (Boyd \& Ellison, 2007). Asimismo, gracias a la emergencia de dichas zonas, las fronteras entre lo privado y lo público se volatilizan suscitando la aparición de una suerte de «esfera pública» online, donde el debate de temáticas de interés social cobra especial notoriedad y la palabra se democratiza, poniendo de relieve la máxima popular «lo personal es político» (Hanisch, 1969), aunque si bien las redes sociales permiten el desarrollo de contramarcos relevantes, a menudo, estos se encuentran con una praxis antifeminista donde «[...] los ataques a las mujeres se [intensifican] de la mano de grupos que generan y difunden mensajes misóginos aunando los atractivos de lo popular y lo digital» (Tortajada \& Vera, 2021: 1).

Retomando el sujeto de esta investigación, en las redes sociales se establece un caldo de cultivo propicio para el surgimiento y cohabitación de los activismos (Casero-Ripollés, 2015) y de los feminismos subalternos, lo que a su vez da lugar a la divulgación de teorías feministas que surgen a partir de la organización y siempre desde los márgenes. Según Bartoski y Grzywińska (2017), citando a Dahlgren (2005), «existen tres dimensiones de la esfera pública online» de las cuales destaca en el marco de esta investigación «la dimensión de representación», lo que permite observar que hay espacios «[...] en línea de discusión alternativos al discurso de los medios de 
comunicación tradicionales, ya que algunos de los que opinan se ven excluidos de los debates políticos convencionales» (Batorski \& Grzywińska, 2017: 358). Así lo afirma la filósofa india Spivak (2003: 298): «[...] el sujeto subalterno habla físicamente, sin embargo, su habla no adquiere estatus de diálogo, el subalterno no es un sujeto que ocupa una posición discursiva desde la que puede hablar o responder». De este modo, las redes sociales digitales permiten que los grupos de personas no hegemónicas silenciadas históricamente por los grupos dominantes -blancos, heterosexuales, occidentales, burgueses (Ballestrin, 2017) - puedan tratar temáticas de su interés y a partir de su autopresentación, lo que sin duda se traduce en un acto de rebeldía y activismo. Asimismo, al tratar cuestiones de interés, y gracias a la creación de un contenido divulgativo e informativo, se desarrolla una retroalimentación que se interpreta en una mayor representatividad y visibilización de los otros feminismos. De esta forma, las redes sociales, como oposición de los medios de comunicación convencionales, pueden asumirse como un contramarco, un espacio por y para la subalternidad.

\subsection{Los otros feminismos}

10 Se denominan feminismos subalternos aquellos que suponen una contestación al feminismo hegemónico occidental, blanco, universalista, eurocéntrico y del primer mundo (Ballestrin, 2017: 1036), siendo su epítome el feminismo canónico que ha silenciado la lucha de la epistemología feminista del sur. Espinosa (2012) afirma que las producciones feministas latinoamericanas no fueron visibilizadas hasta que las académicas del norte no legitimaron su reconocimiento. De nuevo, emerge la idea de Feagin (2020) donde el marco establecido dominante -feminismo del norte- ha imperado en los medios de comunicación, apoderándose de la representación de los estudios de género. Con el objetivo de de-construir el marco dominante y dar visibilidad a sus movimientos, las afrofeministas estadounidenses como Audre Lorde, Angela Davis, Patricia Hill Collins o bell hooks fueron pioneras en la elaboración de los contramarcos.

11 En los años 1980, estas desarrollan la idea de interseccionalidad (Crenshaw, 1991) ${ }^{2}$ como un contramarco. Abogan por una ruptura del feminismo esencialista y la incorporación de las aristas de raza y clase como conceptos trasformadores de la narrativa dominante. A través de las redes sociales, estos contramarcos comienzan a tomar forma de grupos o colectivos que crean espacios seguros -que se concretizan en perfiles de Facebook, YouTube, Twitter o Instagram- para dar acceso a un diálogo divulgativo, empero también de lucha, activismo y denuncia.

12 La esfera pública online se abre a los contramarcos que se materializan en la interacción sincrónica de sociedades que albergan las mismas inquietudes y deseos. Lo privado se convierte en público y viceversa gracias a movimientos que emergen desde las redes sociales como Twitter con el ya mediático \#BlackLivesMatter (Parry, Fullagar \& Johnson, 2019), o movimientos del sur ${ }^{3}$ con \#NiUnaMenos (Revilla, 2018), en referencia a los asesinatos machistas, o incluso \#PañuelazoInternacional en Argentina (Esquivel, 2019) por la solicitud de la ley de aborto.

13 El pasado 8 de marzo, el colectivo dominicano Juntas Prietas realizó la performance ¿Acaso no soy una mujer?, disponible en YouTube, donde abordó de manera magistral el victimismo constante al que el feminismo hegemónico las somete de manera 
sistemática: «¿Acaso no soy sujeta de conocimientos?, ¿es que lo que siento, lo que sentimos, no es parte del conocimiento? o ... ¿ de lo que se conoce por conocimiento?» (Juntas Prietas, 2021). Las construcciones de las contranarrativas que llevan a cabo los feminismos de la otredad permiten confrontar y formar una resistencia activa ante el impuesto marco dominante.

\section{Fotografía, imagen y representación}

Fotografía, pintura, cuadro, dibujo, grabado o litografía son algunos de los términos que engloban el concepto polisémico de imagen (Joly, 2018). El empleo de imagen como genérico para la definición de la expresión visual es algo común y extendido. Sin embargo, imagen también se define como la representación o semejanza de algo. A partir de los estudios de semiología de la imagen, se establece la representación visual como sinónimo de imagen, «[1]a imagen es re-presentación» (Barthes, 1964: 40). La representación es un acto cognitivo a través del cual se produce un signo que se establece como el doble de una supuesta realidad (Szurmuk \& McKee, 2009). Sin embargo, la interpretación y percepción que se realiza de la representación varía en función del sujeto. Hall (2010), en el marco de los estudios culturales, prestará especial atención al estudio de las representaciones partiendo de un enfoque constructivista donde determinará que la representación es una noción determinante para el esquema de comprensión a través del cual los sujetos perciben el mundo. De este modo, se tratará de aplicar dicha definición a las imágenes situadas en las redes sociales que los grupos activistas subalternos emplean como vehículo de sus identidades.

\subsection{La otredad en los marcos}

Las redes sociales como Facebook tienen un componente determinante en su configuración: la imagen. La red social invita a las usuarias y a los usuarios a hacer uso constante de fotografías digitales, cuadros, pinturas, dibujos $u$ otro tipo de elementos de expresión visual. No obstante, en este producir y reproducir constante, se entremezclan las representaciones hegemónicas frente a las auto presentaciones o contra-presentaciones que las usuarias y los usuarios realizan de las temáticas. En los medios de comunicación hegemónicos, a menudo se han llevado a cabo representaciones estereotipadas de los sujetos, retomando «[...] características sencillas, vividas, memorables, fácilmente percibidas y ampliamente reconocidas acerca de una persona [que] reducen todo acerca de una persona a esos rasgos, los exageran y simplifican y los fijan sin cambio o desarrollo hasta la eternidad» (Hall, 2010: 430). Siguiendo la metodología empleada por Hall (1997), ofrecemos a continuación un ejemplo de análisis adaptado a la actualidad.

En 2018, la tenista estadounidense Serena Williams fue fotografiada durante el Abierto de Estados Unidos donde perdió frente a Naomi Osaka (imagen 1). 
Imagen 1.- Serena Williams se enfadó mucho durante la final del Abierto de Estados Unidos. BBC News, 9 de octubre de 2018.

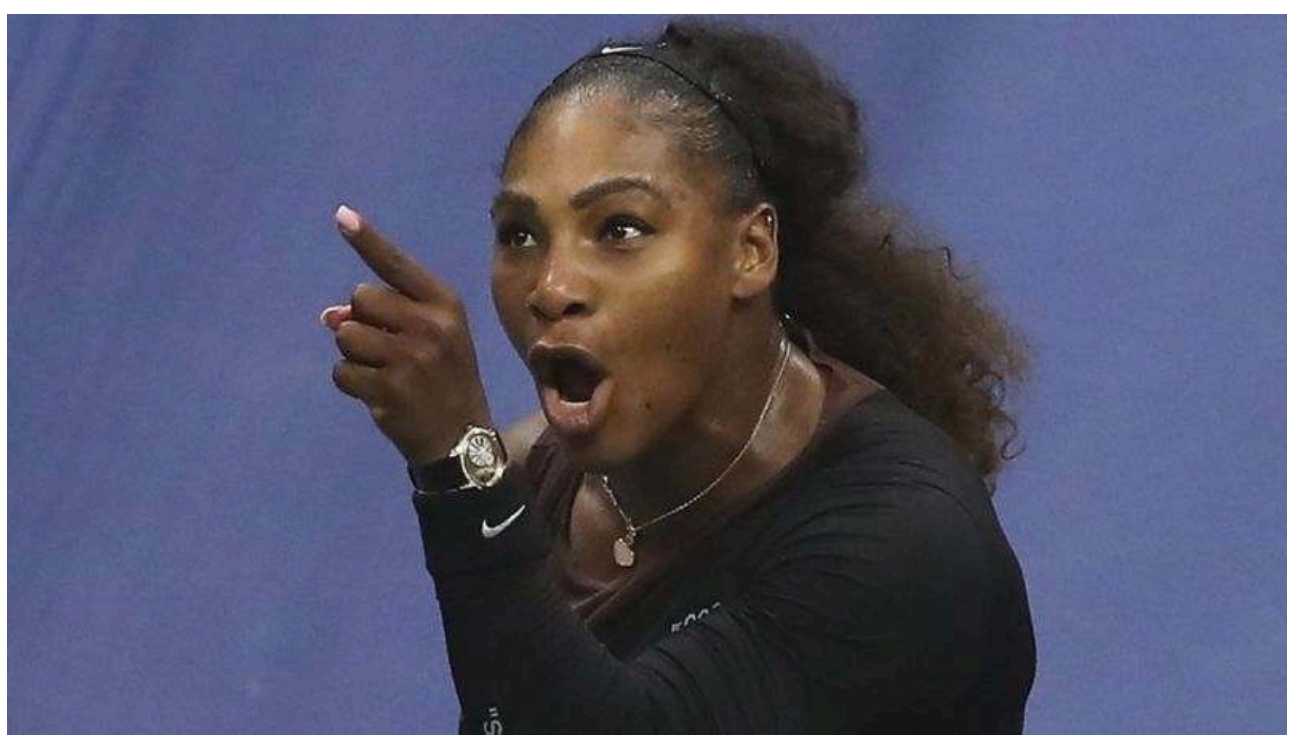

Imagen 2.- Mark Knight's cartoon. Caricatura de Serena Williams realizada por Mark Knight y publicada en The Herald Sun.

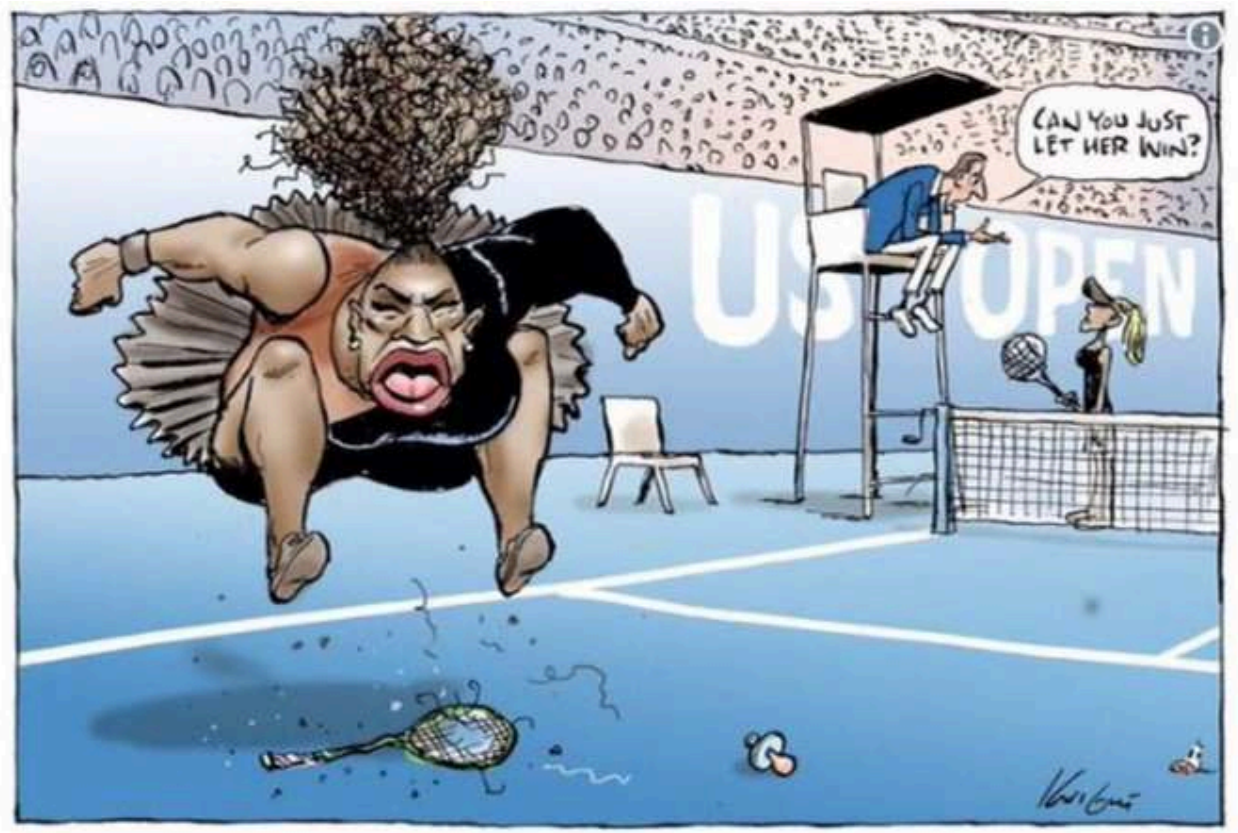

17 La imagen de Williams (imagen 1), siguiendo el esquema analítico constructivo de Hall, evidencia dos aspectos claves. Un primer evento radica en el aspecto denotativo, donde la tenista, claramente enfadada, alza el dedo en señal de desaprobación contra el árbitro que la había acusado de juego desleal. Esta descripción no encarna ningún estereotipo determinado. Sin embargo, el aspecto connotativo llega a posteriori cuando al leer la noticia conocemos que nunca un hombre tenista se había visto amonestar tan duramente por expresar su enfado como lo hizo el árbitro con Williams. El denotativo enfado de Williams se convirtió en un connotativo enfado (imagen 2) publicado en la prensa australiana, que le atribuyó adjetivos como «mal enfado o bad behavior», que retoma el mito de the angry black women, (Jones \& Norwood, 2017) y que apela a la 
famosa era estadounidense de Jim Crow (Feagin, 2020), donde se vierte el imaginario impuesto de mujer violenta, agresiva o salvaje. La estereotipación de las representaciones radica en la construcción de la otredad a partir de una categorización de los conceptos de la cual emana una oposición binaria. Williams aúna una doble discriminación pues encarna dos dimensiones categóricas: género y raza. Como mujer se opone a hombre y como mujer negra se opone a mujer blanca. Lo que cabría preguntarse entonces sería: ¿Cómo se habría percibido esta imagen de haber sido un hombre? ¿Cómo se habría percibido dicha imagen de haber sido una mujer blanca?

18 A través de los juegos de poderes se ha construido un orden social simbólico (Hall, 2010; Feagin, 2020) que se materializa en cada representación. Las redes sociales son los nuevos espacios alternativos a los poderes hegemónicos donde grupos activistas, desde la subalternidad, se autorrepresentan con una contranarrativa resistente a lo normativo.

\subsection{El diálogo de «Paz y Género»: un caso de contramarco}

19 La cuenta de Facebook de @PazyGénero nace en 2017 con el objetivo de compartir la labor que realiza el proyecto asociativo colombiano Escuela Politica: «Travesías por la Paz y la Equidad de Género». Esta cuenta, que se identifica como una organización sin ánimo de lucro, fue creada por diferentes mujeres miembro de dicho organismo y en la actualidad, Catalina Galeano es la encargada del área de comunicación ${ }^{4}$. @PazyGénero se compone de un total de cuatro mil trescientas veintiuna seguidoras o mil trescientos veintiún seguidores y alberga un cuerpo de más de mil imágenes. La mayoría de las publicaciones son compartidas entre diez y veinte veces y los «me gusta» no suelen sobrepasar el centenar. Su trabajo en la red social destaca particularmente por la perspectiva y la contranarrativa claramente activista que defiende. Desde una perspectiva feminista decolonial, aborda las luchas que llevan a cabo «[...] las mujeres indígenas, las mujeres afrodescendientes, las mujeres campesinas, y las mujeres víctimas de desapariciones forzadas o desplazamiento» (Paz, 2003). Las imágenes que proyectan suelen enmarcarse en manifestaciones (imágenes 3,5 y 6), en proyectos de reconocimiento (imagen 4) o en talleres de educación. 
Imagen 3. - 20 de octubre de 2020. La Minga Indígena ${ }^{5}$. @PazyGénero <https://www.facebook.com/PazyGenero/photos/3500668633305687/>

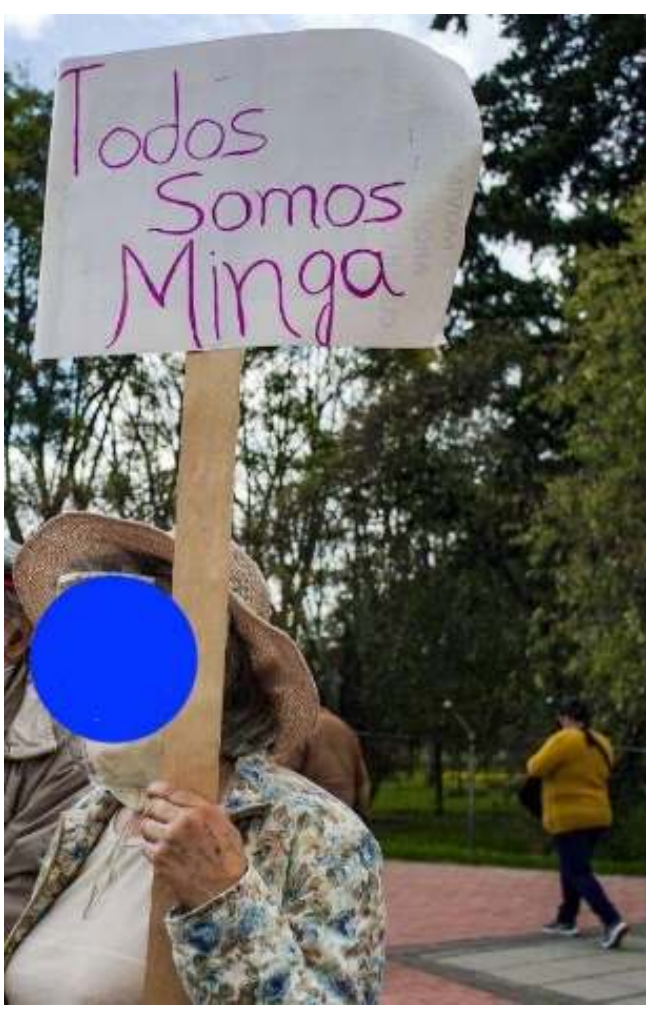

Imagen 4. - 2 de septiembre de 2019. \#LideresasPorLaVida\#CampañaSurOccidente \#JuntasPodemos Campaña Honrar la vida. @PazyGénero <https://www.facebook.com/PazyGenero/photos/2481204118585482/>

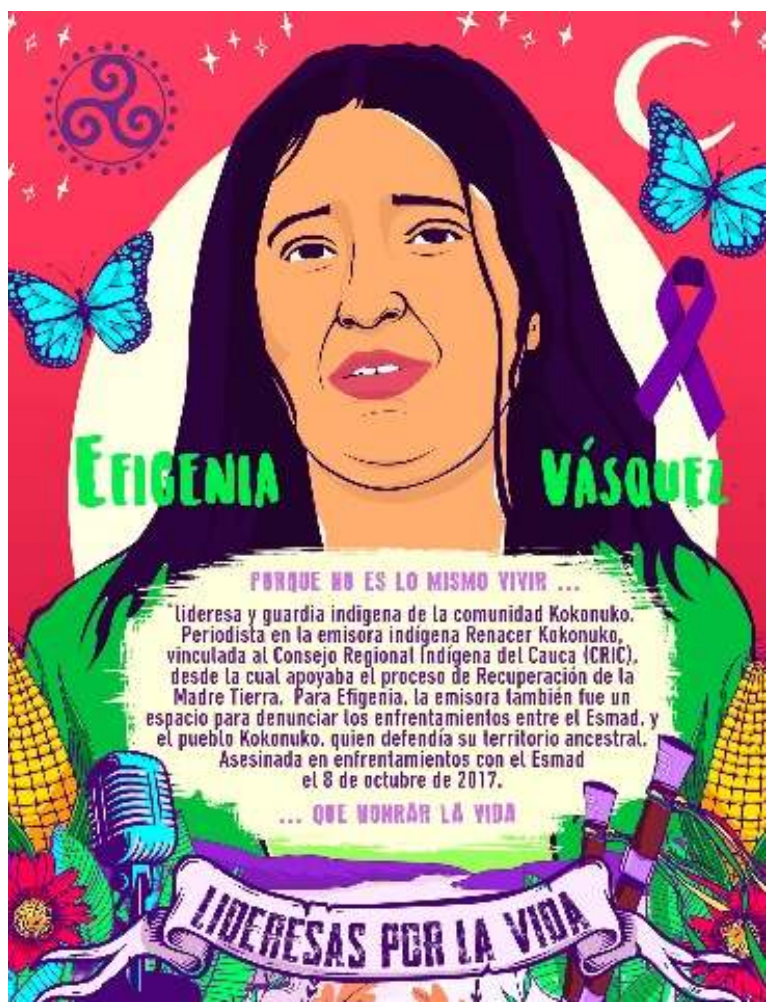


Se caracteriza esta cuenta por la especial relevancia que toman las manifestaciones de las mujeres colombianas, donde la gran mayoría de las fotografías está protagonizada por mujeres indígenas (imagen 4) o afros (imágenes 5 y 6). Varias imágenes destacan en relación con las manifestaciones realizadas por La Minga Indígena (imagen 3) a lo largo del 2020 con el objetivo de reclamar sus derechos. Su activismo se acciona gracias al empleo del espacio público (Fraser, 1990) ${ }^{6}$ online para el tratado de temáticas que afectan al bien común. Generan contranarrativas en oposición a los medios hegemónicos, reapropiándose de los dispositivos digitales en favor de sus comunidades (Cardoso \& Da Silva, 2020). «Todos somos minga» es un lema que retoma la idea de autodefinición y además pone de realce la invisibilización que sufren las comunidades indígenas. Con el objetivo de ser escuchadas, se solidarizan a través de eslóganes que las reagrupan dentro de la individualidad colectiva.

21 En Lideresas por la vida (imagen 4) el activismo se refleja en «[...] la intención [...] de vivificar y reivindicar la lucha cotidiana, constante y aguerrida de las mujeres por la defensa de sus territorios» (@PazyGénero, 2020). Se trata de un proyecto constituido por cincuenta imágenes de diferentes lideresas de la región del pacífico y el suroccidente colombiano ${ }^{7}$ de las cuales una parte fue asesinada por su lucha. La imagen de Efigenia Vásquez (imagen 4), lideresa de la comunidad Kokonuko, reza «[sic] ¡merecer la vida no es callar y consentir tantas injusticias repetidas ... es una virtud, es dignidad y es la actitud de identidad más definida!». En esta frase, se retoma el concepto de identidad como liberación del yo (Giddens, 1995) a través de un proceso de desarrollo desde el pasado a un futuro (Giddens, 1995). Históricamente la etapa colonial fue determinante para la construcción de las representaciones actuales estigmatizadas en el sentido goffmaniano. Los contramarcos activos de lo privado - «se juegan la vida misma en acciones transformadoras resignificando su contenido político e histórico, convencidas que no es lo mismo vivir que honrar la vida» (@PazyGénero, 2020) - se materializan en los contramarcos de lo público. La protección y re-construcción de los territorios -Campaña sur occidente y pacífico, «nuestra región», título presente en la imagen 4 es la r(e)construcción de una identidad a través del recuerdo: «jEfigenia no te enterramos te sembramos!» (@PazyGénero, 2019).

En la heterogeneidad de las luchas de «Paz y Género» se destaca la adaptabilidad contranarrativa a la situación social pública. A continuación, observamos dos imágenes que ejemplifican las construcciones del contramarco. 
Imagen 5. - 12 de septiembre de 2020. Las vidas de la gente negra importan. @PazyGénero <https://www.facebook.com/PazyGenero/photos/3385129018192983/>

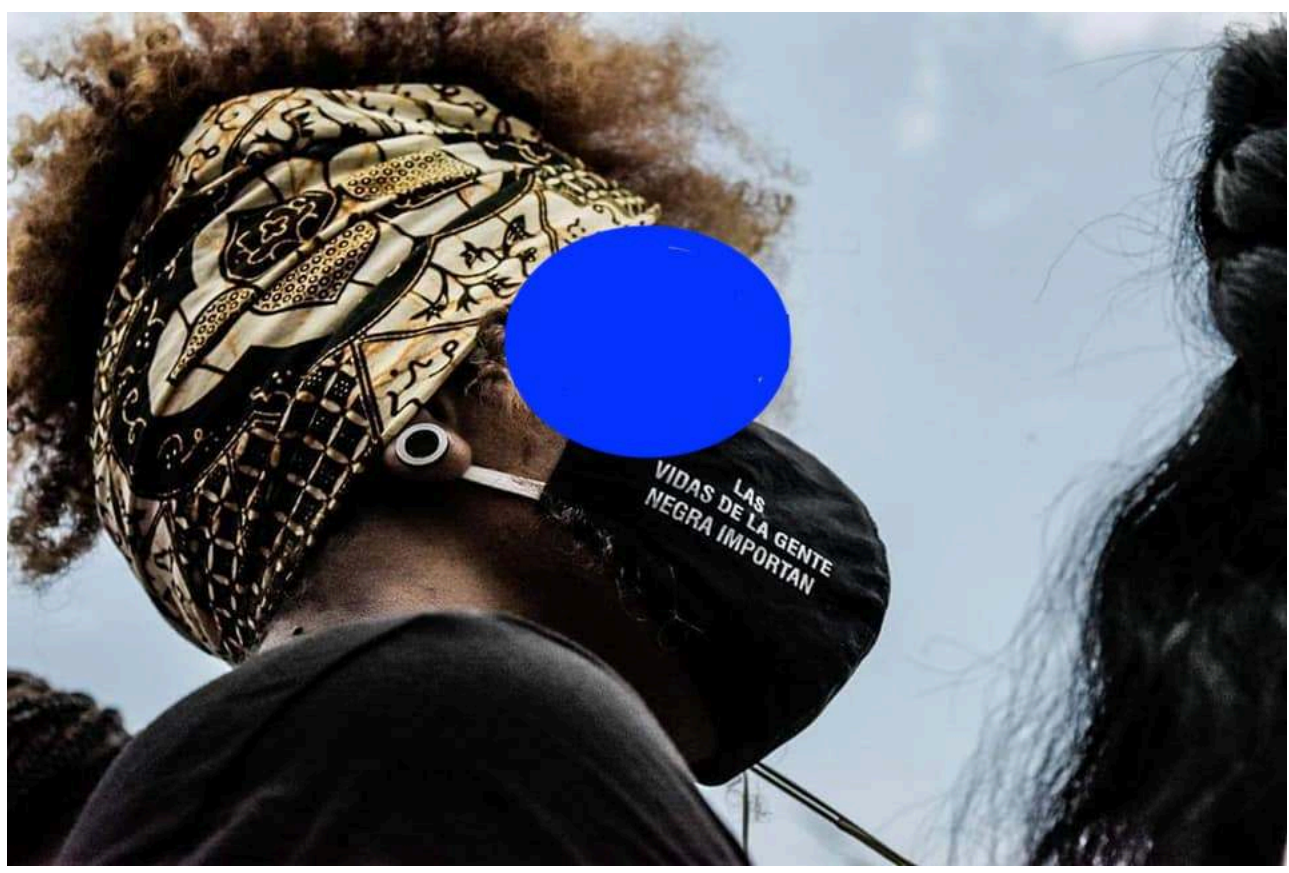

Imagen 6. - 20 de agosto de 2020. La bendita prietitud. @PazyGénero <https://www.facebook.com/PazyGenero/photos/3313065585399327/>

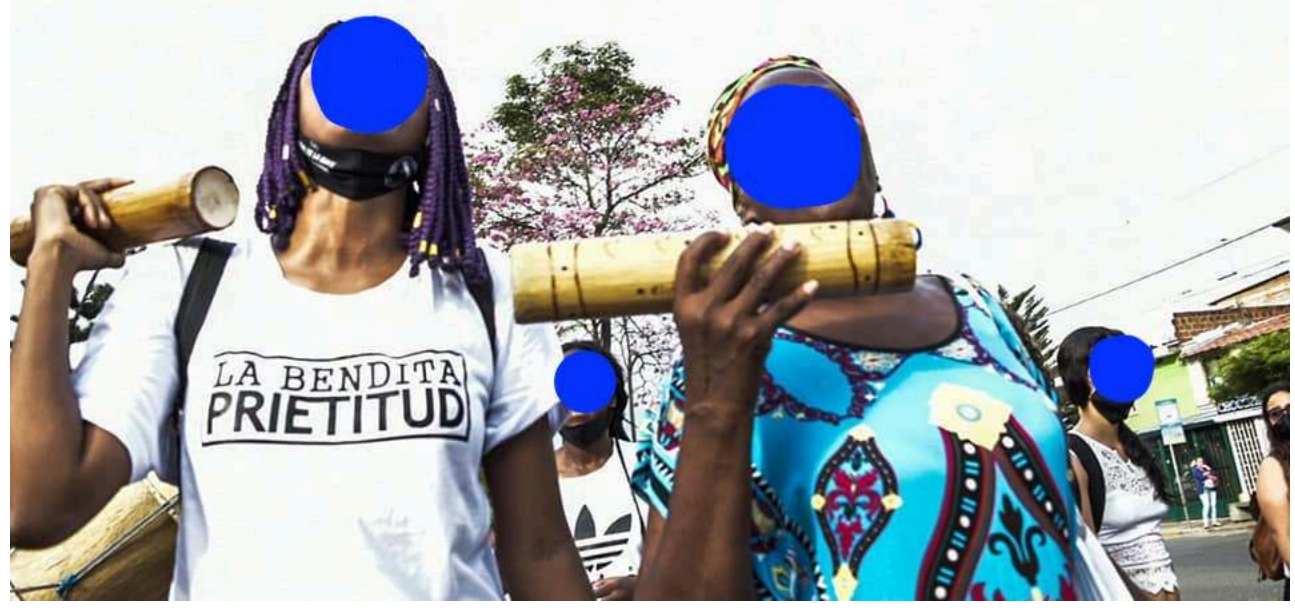

En agosto de 2020, cinco jóvenes negros fueron asesinados en Llano Verde, uno de los barrios de la periferia de Cali. Un mes más tarde, asociaciones y agrupaciones locales se manifestaron para exigir justicia. «Paz y Género» retransmitió la manifestación a través de las fotografías publicadas en su cuenta de Facebook. En la primera imagen (5), observamos un primerísimo plano con un ángulo contrapicado de una de las manifestantes, poniendo de realce el perfil derecho de su mascarilla que reza «las vidas de la gente negra importan» (imagen 5). Esta frase determina la auto presentación que 
las comunidades afrodescendientes colombianas claman en respuesta activa a las violencias policiales e institucionales, esta última en sentido literal, estado, y figurado, sociedad. Desde las élites, existe una voluntad de representación determinada que se materializa en la expulsión del Otro simbólicamente, aunque también stricto sensu como es el caso de la descentrificación geográfica ${ }^{8}$, donde se sitúa a la otredad en el margen. Los órdenes sociales históricos han constituido un marco racial blanco (Feagin, 2020) a partir de la diferencia, de la estigmatización (Goffman, 2006) donde el yo existe por oposición al Otro. Hall (2010) aborda una explicación ejemplificadora de los marcos. La epistemología occidental, marco dominante, ha contribuido a la construcción de identidades imperantes, empero la praxis establecida por los activismos subalternos de la actualidad permite que las divisiones asentadas se disipen y las identidades se reescriban. El sexismo, la homofobia, la transfobia o el racismo entre otros son discriminaciones que se cuestionan actualmente con vehemencia. Por su parte, «Bendita prietitud» (imagen 6) retoma plenamente el concepto de identidad como reconstrucción de la representación. Tres mujeres afro protagonizan la segunda imagen (6), dos de ellas figuran en un primer plano medio corto y en un segundo plano observamos a la tercera. De igual modo, a la derecha se observa a dos mujeres blancas unidas a la manifestación. A través de un leve ángulo contrapicado, la fotografía permite fortalecer la impresión de realidad y la naturalización de la escena (Joly, 2018); retoma plenamente el concepto de identidad como reconstrucción de la representación desarrollando un movimiento desde la subalternidad donde las mujeres afrodescendientes reescriben su trayecto y proporcionan representaciones que emanan a partir de sí mismas. A través de estas imágenes, se establece un diálogo claramente opuesto a la realidad habitual hegemónica imperante, permitiendo de este modo un cambio y una reconquista del espacio público históricamente ocupado por el racismo, el machismo y la discriminación de manera general.

En las publicaciones, a pesar de la leve popularidad (4 321 seguidores), se destacan los comentarios de apoyo de otras mujeres hacia la organización: «Bellísimo y oportuno lanzamiento otra verdad que renace como el ave fénix entre las cenizas de esta guerra sin cuartel. Vencerá la Vida. La Verdad nos hará libres»; «vivas nos queremos» o incluso «unidas y sin miedo» (@PazyGénero, 2020).

Tanto los comentarios precedentes como el análisis realizado sobre las cuatro fotografías refuerzan diversas hipótesis planteadas inicialmente.

En la actualidad, los espacios en línea y especialmente las redes sociales han permitido constituir en el mundo online una esfera pública cuyas principales características son la representación visual o gráfica, a través de imágenes o eslóganes, y los discursos de interés público en el sentido más extenso. Retomando el objeto de estudio de este trabajo, la imagen y en particular la fotografía se ha constituido en un medio de comunicación en su totalidad, tanto por el aspecto visual como por el aspecto narrativo del discurso. La fotografía ha sido el elemento empleado por las cuentas de Facebook investigadas como objeto a través del cual han podido re-construir su historia y por inferencia su identidad. Los marcos dominantes han constituido las narrativas de la otredad durante mucho tiempo, empero los contramarcos surgen desde los márgenes con el objetivo de cuestionar la historia contada y escribirla de nuevo, esta vez para y por sí mismas. 


\section{Conclusión}

La toma de conciencia de la necesidad de la lucha por parte de los feminismos subalternos dentro y fuera de las redes sociales es ostensible. Con el objetivo de comprender cómo se han construido estos feminismos se ha abordado la dicotomía de los (contra)marcos. En un inicio, se ha tratado el estudio del marco imperante a través de dos imágenes publicadas en la prensa australiana donde se pudo observar claramente la persistencia de una visión connotada en la estigmatización a partir de la doble dimensión de género y raza. Seguidamente, y con el objetivo de conocer cómo se han constituido los contramarcos, se ha tratado el estudio de caso de una cuenta de Facebook colombiana que, desde la decolonialidad y la subalternidad, ha mostrado cómo ha reconfigurado la identidad, donde la otredad se ha constituido a partir de la diferencia. Dicho análisis ha permitido observar que las redes sociales no son únicamente espejos de una realidad, sino que son verdaderos espacios públicos de creación, de estudio, de (de)construcción y (re)construcción de nuevas realidades. Los feminismos subalternos evocan sus re-presentaciones, las de la otredad, empero también abordan las representaciones del marco dominante, donde por primera vez, son los contramarcos los que cuestionan los marcos:

Descolonizar el feminismo es volver a mirar al patriarcado en su complejidad, como el sistema de todas las opresiones; no es un sistema más, es el sistema que oprime a la humanidad y a la naturaleza, construido históricamente y todos los días sobre el cuerpo de las mujeres.

Adriana Guzmán Arroyo (<https://utopix.cc/pix/adriana-guzman-arroyo/>)

\section{BIBLIOGRAFÍA}

BAKARDJIEVA Maria (2009), «Subactivism: Lifeworld and Politics in the Age of the Internet», The Information Society, 25(2), 91-104, <https://doi.org/10.1080/01972240802701627>.

BALLESTRIN DE ARAGÃo Luciana Maria (2017), «Feminismos subalternos», Revista Estudos Feministas, 25(3), 1035-1054, <https://doi.org/10.1590/1806-9584.2017v25n3p1035>.

BARTHES Roland (1964), «Rhétorique de l'image», Communications (4), 40-51, <https://doi.org/ 10.3406/comm.1964.1027>.

BATORSKi Dominik \& GRZYWINSKA Ilona (2018), «Three dimensions of the public sphere on Facebook», Information, communication and society, 21(3), 356-374, <https://doi.org/ 10.1080/1369118X.2017.1281329>.

BRENNE Sarah (2016), «Political discussion on social media and the public sphere», Sociology and anthropology, 4(4), 270-275, <https://doi.org/10.13189/sa.2016.040410>.

BoYD Danah \& ELLISON Nicole (2007), «Social network sites: Definition, history, and scholarship», Journal of compu-ter-mediated communication, 13(1), 210-230, <https://doi.org/10.1111/j. 1083-6101.2007.00393.x>. 
CARDOSO FRANCO Thiago \& DA SILVA Marcelo Rodrigo (2021), «Cosmofagia e net-ativismo indígena brasileiro, durante a pandemia da Covid-19», Chasqui. Revista Latinoamericana de Comunicación (145), 181-196, <https://revistachasqui.org/index.php/chasqui/article/view/4346>.

CASERO-RIPOLLÉS Andreu (2015), «Estrategias y prácticas comunicativas del activismo político en las redes sociales en España», Historia y comunicación social, 20(2), 533-548, <https://doi.org/ 10.5209/rev_HICS.2015.v20.n2.51399>.

CHAKRAVORTY SPIVAC Gayatri (2003), «¿Puede hablar el subalterno?», Revista colombiana de antropología, 39, 297-364, <https://www.redalyc.org/pdf/1050/105018181010.pdf> (2 de marzo de 2021).

CRENSHAW Kimberlé (1991), «Mapping the Margins: Intersectionality, Identity Politics, and Violence Against Women of Color», Stanford Law Review, 43(6), 1241-1299, <https://doi.org/ $10.2307 / 1229039>$.

DENZIN Norman K. \& LINColn Yvonna (2012), Manual de investigación cualitativa: El campo de la investigación cualitativa: Manual de investigación cualitativa Vol. I, Barcelona: Gedisa Editorial.

DORLIN Elsa (2009), La matrice de la race. Généalogie sexuelle et coloniale de la Nation française, Paris: Éditions La Découverte.

ESPINOSA MiÑoso Yuderkis (2009), «Etnocentrismo y colonialidad en los feminismos latinoamericanos: complicidades y consolidación de las hegemonías feministas en el espacio transnacional», Revista venezolana de estudios de la mujer, 14(33), 37-54, <http://ve.scielo.org/ scielo.php?pid=S1316-37012009000200003\&script=sci_abstract $>$ (2 de marzo de 2021).

ESPINOSA MiÑoso Yuderkis (2017), «Hacia la construcción de la historia de un (des)encuentro: la razón feminista y la agencia antirracista y decolonial en Abya Yala», Praxis. Revista de filosofía (76), 25-39, <http://dx.doi.org/10.15359/praxis.76.2>.

ESQUivel DomínguEz Daniela Carolina (2019), «Construcción de la protesta feminista en hashtags: aproximaciones desde el análisis de redes sociales», Comunicación y Medios, 28(40), 184-108, $<$ https://scielo.conicyt.cl/scielo.php?script=sci_arttext\&pid=S0719-15292019000200184> (2 de marzo de 2021).

FEAGIN Joe Richard (2020), The White Racial Frame: Centuries of Racial Framing and Counter-Framing, New York: Routledge.

FRASER Nancy (1990), «Rethinking the Public Sphere: A contribution to the Critique of Actually Existing Democracy», Duke University Press (25/26), 56-80, <https://doi.org/10.2307/466240>.

GIDDENS Anthony (1995), Modernidad e identidad del yo, el yo y la sociedad en la época contemporánea, Barcelona: Península.

GofFMAN Erving (2006), Estigma. La identidad deteriorada, Madrid: Amorrortu editores.

HABERMAS Jürgen (1989), The Structural Transformation of the Public Sphere, Cambridge: The Mit Press.

HALL Stuart (1973), «Encoding and decoding in the television dicourse», paper for the Council of Europe Colloquy on Training in the Critical Reading of Televisual Language, Centre for Contemporary Cultural Studies, Birmingham.

HALL Stuart (1997), Representation: cultural representations and signifying practices, London: Sage, The Open University. 
HALL Stuart (2010), Sin garantías: Trayectorias y problemáticas en estudios culturales, Universidad Andina Simón Bolívar: Ecuador.

HANisch Carol (1969), «The Personal Is Political», B. A. Crow (dir.), Radical Feminism: A Documentary Reader, New York: New York University Press, 9, 113-117.

HooKs BeLl (2020), Teoría feminista: de los márgenes al centro, Madrid: Traficantes de sueños.

Joly Martine (2018), Introduction à l'analyse de l'image, Malakoff: Armand Colin.

JONES Trina \& NORWOOD Jade Kimberly (2017), «Aggressive Encounters \& White Fragility:

Deconstructing the Trope of the Angry Black Woman», Iowa Law Review (102), 2017-2069, <https:// scholarship.law.duke.edu/faculty_scholarship/3761/> (2 de marzo de 2021).

MASIP Pere, Ruiz CABALlero Carlos \& SUAU Jaume (2019), «Active audiences and social discussion on the digital public sphere», El profesional de la información, 28(2), <https://doi.org//10.3145/epi. 2019.mar.04>.

Martínez Tovar Jimara, Pomares Dayrina, Sierra Mauricio \& Martínez María G. (2020), «Racismo y segregación en Colombia [sic]: salud, educación y trabajo en la población afrodescendiente del pacífico», Trans-pasando fronteras (16), 93-122, <https://doi.org/10.18046/retf.i16.4102>.

OLSON Reilly E. (2021), «Roles of Social Media in the Black Lives Matter Movement During COVID-19», Honors Projects (838), <https://scholarworks.gvsu.edu/honorsprojects/838/? utm_source=scholarworks.gvsu.edu\%2Fhonorsprojects\%2F838\&utm_medium=PDF\&utm_campaign=PDFCoverPages> (21 de junio 2021).

PARRY Diana, FUlLAGAR Simone \& JoHnSon Corey (2019), Digital dilemmas: Transforming gender identitites and power relations in everyday life, Switzerland: Palgrave Macmillan, <https://doi.org/ 10.1007/978-3-319-95300-7>.

PAZ GómEz Melisa [coord.] (2003), Travesía por la paz, en línea en <https:// corporacionparaeldesarrolloregional.org/wp-content/uploads/2018/10/Travesia-por-la-PazISBN.pdf> (6 de marzo de 2021).

Revilla Blanco Marisa (2019), «Del ¡Ni una más! al \#NiUnaMenos: movimientos de mujeres y feminismos en América Latina», Política y Sociedad, 56(1), 47-67, <https://doi.org/10.5209/poso. 60792>.

SZURMUK Mónica \& MCKEE Robert (2009), Diccionario de estudios culturales latinoamericanos, México: Siglo XXI, Instituto Mora.

Tortajada Iolanda, Caballero-Gálvez Antonio \& Willem Cilia (2019), «Contrapúblicos en YouTube: el caso del colectivo trans», El profesional de la información, 28(6), <https://doi.org/10.3145/epi. 2019.nov.22>.

TORTAJADA Iolanda, CABAllero-GÁlvez Antonio \& Willem Cilia (2021), «Feminismo, misoginia y redes sociales», Investigaciones feministas, 12(1), <https://dx.doi.org/10.5209/infe.74446>.

Zuluaga Cometa Alejandro (2010), «Construir país, el país de los pueblos, la minga», Kavilando, 2(1), 46-80, ISSN: 2027-2391, <https://dialnet.unirioja.es/servlet/articulo?codigo=3627193> (6 de marzo de 2021). 


\section{NOTAS}

1. Se entiende feminismos de los márgenes como sinónimo de feminismo subalterno, es decir, los feminismos antagonistas al feminismo elitista y hegemónico. (Ballestrin, 2017)

2. El término interseccional fue empleado por primera vez por la jurista estadounidense Kimberlé Crenshaw en su artículo Mapping the Margins. Proviene del sustantivo intersección y se refiere al encuentro entre la raza, la clase y el sexo: «I used the concept of intersectionality to denote the various ways in which race and gender interact to shape the multiple dimensions of Black women's employment experiences» (Crenshaw, 1989: 139).

3. Con el término movimientos del sur nos referimos a la contextualización geográfica y no social basándonos en las teorías de Yuderkis Espinosa, donde los feminismos del sur no deben ser comprendidos como un sujeto monolítico. (Espinosa, 2017)

4. La organización Corporación para el desarrollo regional cuenta con una directora ejecutiva, Martha Burbano, y una coordinadora del proyecto Vivir en paz desde la co-inspiración comunitaria, María Eugenia Betancur. En el seno del proyecto, Catalina Galeano se encarga del área de comunicación.

5. La Minga Indígena es un movimiento de la comunidad indígena colombiana que protesta con el objetivo de exigir sus derechos a través de movilizaciones. (Zuluaga, 2010)

6. Cuando «Paz y Género» u otras cuentas activistas emplean el espacio público como lugar de denuncia, cuestionan el concepto original habermasiano de la esfera pública. Para Nancy Fraser «[...] una concepción adecuada de la esfera pública requiere no simplemente una puesta en paréntesis de las desigualdades sociales, sino, su eliminación, frente a la concepción burguesa como ideal normativo.» (Fraser, 1990: 172)

7. La región del pacífico colombiano destaca por su población mayoritaria afrodescendiente e indígena (Martínez, Pomares, Sierra \& Martínez, 2020: 96).

8. Valle Verde nace hace 10 años en los cañizales de Cali como barrio formado principalmente por desplazadas y desplazados víctimas del conflicto armado.

\section{RESÚMENES}

Las redes sociales son espacios de comunicación sincrónica y plataformas de interacción social. Facebook, Instagram, Twitter o YouTube, en un intercambio de conocimientos y prácticas socioculturales, han hecho de las imágenes un medio de expresión alternativo. Con un enfoque subalterno, los colectivos feministas latinoamericanos han encontrado en las redes sociales un universo de intercambio, convivencia y conectividad segura. Su discurso se libera a través de la fotografía, expresión de su pensamiento e identidad. Este artículo se centra en el estudio de caso de la cuenta de Facebook «Paz y Género». Las redes sociales permiten la emergencia de cosmos de intereses y preocupaciones comunes, dando lugar a que estas cuentas puedan denunciar o servir de testimonio de su vida cotidiana. Se analizará su producción visual con el fin de comprender su apropiación de las redes alternativas, así como su trabajo de visibilidad identitaria tomando como punto de partida el feminismo decolonial, una respuesta al feminismo hegemónico.

Espaces de communication synchrone, les réseaux sociaux sont des plateformes d'interaction sociale. Facebook, Instagram, Twitter ou encore YouTube, dans un échange de savoirs et pratiques socio-culturels, ont fait de l'image un moyen alternatif d'expression. Depuis une place 
subalterne, des collectifs féministes latino-américains ont trouvé sur les réseaux sociaux un espace sûr de partage, de cohabitation et de connectivité. Leur parole se libère à travers la photographie, expression de leur pensée et leur identité. Cet article portera sur l'étude de cas du compte Facebook «Paz y Género ». Les réseaux sociaux vont permettre de créer un univers d'intérêts et d'inquiétudes communes permettant la dénonciation et le témoignage de leur quotidien. Nous allons analyser leur production visuelle afin de comprendre leur démarche d'appropriation des réseaux alternatifs ainsi que leur travail de visibilité identitaire qui prend comme point de départ le féminisme décolonial, une remise en question du féminisme hégémonique.

Social networks are platforms of social interaction that use synchronous communication means. Facebook, Instagram, Twitter or YouTube, in an exchange of socio-cultural knowledge and practices, have made the image an alternative means of expression. In a subaltern spirit, Latin American feminist collectives have found on social networks a universe of sharing, cohabitation and safe connectivity. Their speech is liberated through photography: expression of their thought and identity. This article will focus on the case study of "Paz y Género" Facebook account. The social networks will allow the creation of a cosmos of common interests and concerns promoting the denunciation and the testimony of their daily life. We are going to analyze their visual production in order to understand their approach of appropriation of alternative networks as well as their work of identity visibility taking as a starting point the decolonial feminism, a questioning of hegemonic feminism.

\section{ÍNDICE}

Keywords: social networks, representation, image, feminisms, subaltern feminism Mots-clés: réseaux sociaux, représentation, image, féminismes, féminisme subalterne

Palabras claves: redes sociales, representación, imagen, feminismos, feminismo subalterno

\section{AUTOR}

\section{CRISTINA GARCÍA MARTÍNEZ}

Univ. Grenoble Alpes, ILCEA4, 38000 Grenoble, France et Universitat Rovira i Virgili

cristina.garcia-martinez@univ-grenoble-alpes.fr 